\title{
Properties, Characterizations and Applications of Organometallic Surfactants-A Review
}

\author{
Saminu M. Magami' ${ }^{1}$ Zaharaddeen N. Garba' ${ }^{2}$, Mansur B. Ibrahim ${ }^{3}$ \\ ${ }^{1}$ Department of Chemistry, Northwest University, Kano, Nigeria \\ ${ }^{2}$ Department of Chemistry, Faculty of Science, Ahmadu Bello University, Zaria, Nigeria \\ ${ }^{3}$ Department of Pure and Industrial Chemistry, Bayero University, Kano, Nigeria \\ Email: smnmagami@yahoo.co.uk, dinigetso2000@gmail.com, ibrahimm4571@buk.edu.ng
}

Received 7 October 2015; accepted 26 October 2015; published 29 October 2015

Copyright (C) 2015 by authors and Scientific Research Publishing Inc.

This work is licensed under the Creative Commons Attribution International License (CC BY). http://creativecommons.org/licenses/by/4.0/

(c) (i) Open Access

\begin{abstract}
This review focuses on organometallic surfactant frameworks considering their wide applications. Organometallic surfactants have grown from being used as dewaxers in complex industrial processes to the production of nanoparticles and for use in many drug delivery applications. Their properties such as self assembly, forming supramolecular structures are outstanding, providing for their myriad industrial usage. In this review, an account of properties, preparation techniques, characterisation techniques and uses of organometallic surfactants are covered.
\end{abstract}

\section{Keywords}

Organometallic, Surfactants, Drug-Delivery, Nano-Particles, Amphiphilic

\section{Introduction}

Organometallic surfactants are materials based on metal-organic frameworks. They are not complexes in the sense of a metal ion chelated by organic ligands. As surfactants they are generally considered to have surface activity. Compositionally, they are consisting of basically a hydrophilic part and a hydrophobic part in their structure [1] [2]. They are typically considered to have dispersant characteristics [3]. This dispersant character allows for their use as additive materials in surface coatings where dispersion stability is a key requirement. Studies have indicated that these surface active species have the ability to undergo self-assembly in certain solvents into various structures [4]-[6]. The range of solvents covers organic solvents as well as inorganic solvents. 


\section{Composition}

Compositionally, the metallic component of organometallic surfactants can be based on transition metals or non-transition metals. Transitional metal containing materials are more commonly known and these are typically first or second raw transition metals (d-block elements of the periodic table) with other accounts involving the lanthanides. Most of the surfactants that fall under the transition metal category contain one or more of elements including Scandium (Sc) [7], Titanium (Ti) [8]-[10], Vanadium (V) [10] [11], Chromium (Cr) [9], Iron (Fe) [12] [13], Cobalt (Co) [14], Nickel (Ni) [15], Copper (Cu) [16], Zinc Zn [17], Yttrium (Y) [9], Zirconium (Zr) [8] [18] [19], Niobium (Nb) [20], Palladium (Pd) [15], Silver (Ag) [6], Lanthanum (La), Europium (Eu), Gadolinium (Gd), Ytterbium (Yb) [21], Hafnium (Hf) [8] and Osmium (Os) [22]. Similarly, there are a number of reports on non-transition metal-based organometallic surfactants. Some of those recorded included those based on Boron (B) [18], Aluminium (Al) [19], Tin (Sn) and Antimony (Sb) [8].

Some studies have demonstrated double-metal surfactant templates, for example, in the preparation of mesoporous materials [18] and those of double metal surfactant films such as between Zinc and Zirconium [23]. A binuclear Palladium-based organometallic with a highly branched structure has also been reported [24]. Although there are direct synthetic techniques for preparing organometallic surfactants, Liang G. D., and his coworkers see the synthesis of some organometallic nanoshells as challenging [13].

As it has been demonstrated above, there are many literature reports on the synthesis, characterisation or application of organometallic surfactants. However, it can be argued that "a detailed understanding of the metalsurfactant interaction for many products is missing” [25]. Nonetheless, the amphiphilic nature of these kinds of organometallics can allow for a certain degree of interpretations. Figure 1 shows the structure of an Osmiumbased organometallic with Figure 2 showing its molecular structure and elemental distribution [22]. Figure 3 shows the structure of an Iron-based organometallic surfactant which was used in the synthesis of some Prussian Blue (PB) nanoshells via miniemulsion periphery polymerisation (MEPP) [13]. In these surfactant materials, polar groups (e.g. COO group) ionic groups (e.g. quaternary groups) and non-polar groups (e.g. methyl group)

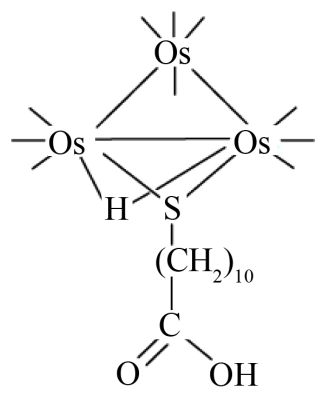

Figure 1. The structure of an osmium-based organometallic.

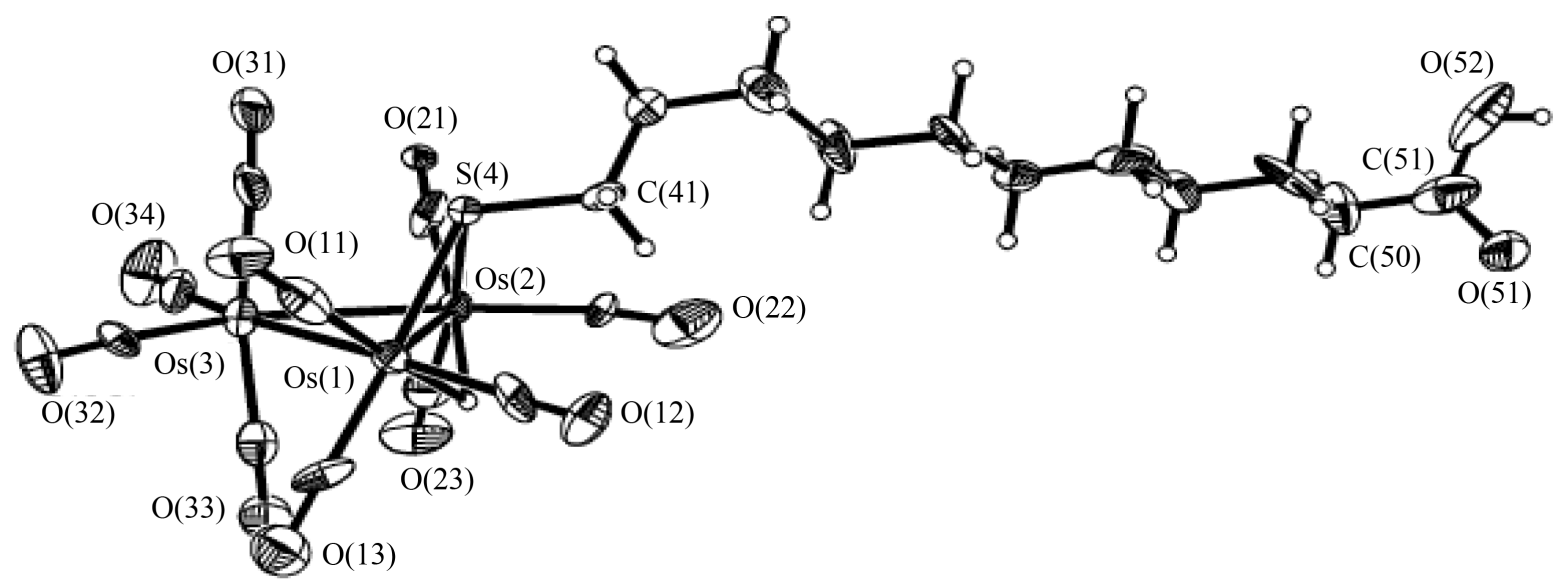

Figure 2. Symmetry and elemental distribution of an osmium-based organometallic. 


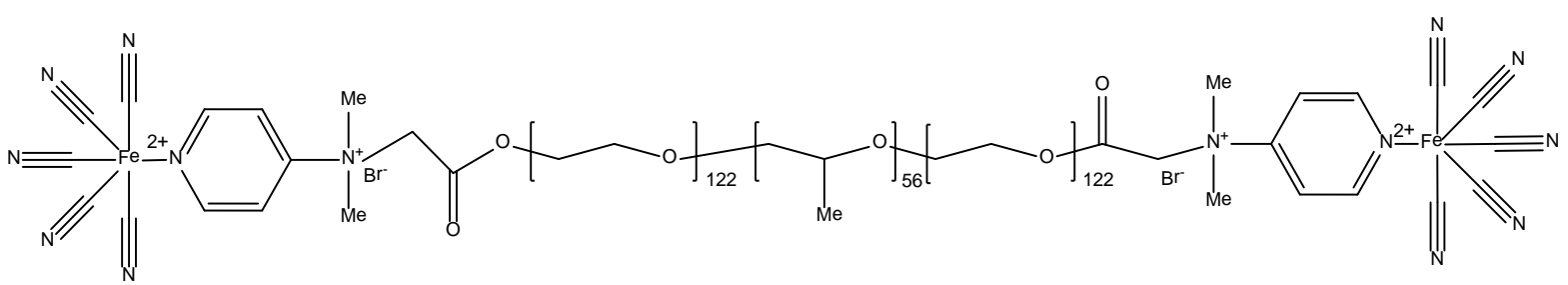

Figure 3. Structure of prussian blue, an iron-based organometallic.

can be seen. The polar groups allow for interactions with other molecules such as water through hydrogen bonding while the ionic species allow for interactions through ionic bonding. Both types of interactions are thermodynamically characterized with lower bonding strength in comparison to covalent interactions and therefore they can be formed or broken depending on conditions such as temperature.

\section{Properties}

Amongst the most commonly identified characteristics of organometallic surfactant are their physiochemical properties and biological activities [26]-[28]. Some reports indicated their encapsulating properties [8], narrow particle size distribution characteristics [29] and Carbon (iv) oxide solubility tendencies [6]. Trickett, K., et al. considered the carbon (iv) oxide $\left(\mathrm{CO}_{2}\right)$ solubility of some few transition metal surfactants as a drawback over a host of others and remarked that earlier studies have only attributed such a problem only to "nonfluorous organometallic surfactants” [6]. It has also been argued that the self-assembly properties of these molecules contribute immensely to their success. The self-assembly property has also been considered to be a means of generating "supramolecular assemblies" which pave a way for the many applications of these materials [5]. Research has also indicated that the metal containing property of organometallic surfactants has given them more opportunities to form various structures and has opened a door for them in terms of performance related properties compared to their non-metal containing surfactant counterparts [14].

According to Lang and Tuel (2002), the metal elements for a greater number of the transition metals have no bearing effect on the orientation of many of the frameworks [10]. On the other hand, some studies have indicated that a variation in chain length of the hydrophobic alkyl component (the hydrocarbon chain) of some surfactants and a variation between halide anions have direct influence on the catalytic activities of some studied organometallic surfactants [16]. Other properties which vary from one surfactant to another and considered to be having significant effect on their chemical or physical properties are the degree of coordination between the metal and the organic ligand [30] and their structure [9]. Magnetic properties have also been found to affect the stability of metal surfactants. Most transition metal surfactant colloids are considered to be magnetic. The magnetic property of organometallic surfactants has led to their use as commercial devices [8].

There is still ongoing research in the structure-based applications of organometallic surfactants [31]. Their drug loading ability, for example, when used in drug delivery purposes may depend on their composition and encapsulation. Organometallic drugs in this category include Ferrocenyl diphenol temoxifen [26]. Regarding their application in new difunctionalised materials, Sakai et al. (2008) have the view that their instability was the result of the non-interest in them in the past years. Organometallic surfactants have other properties such as tissue binding ability, although, this may depend on their structure [31].

\section{Property-Related Opportunities}

Despite the many remarkable properties of organometallic surfactants [32], they are known to decompose on heating and this has paved a way for their use as precursors in the production of nanoparticles [12] [15] [17] [33]-[35]. This particular property has allowed scientific workers the advantage of exploring new materials from surfactant pre-cursors. Son and co-workers (2004) produced some nanoparticles from two surfactant staring materials which only differ in their metal composition (Palladium and Nickel) under the same experimental conditions. The sizes of the nanoparticles produced differ. Those from the Palladium precursors were much smaller than those from their Nickel counterparts. The researchers concluded that Palladium nanoparticles are more difficult to synthesize than those of Nickel, because Nickel metal was easier to form in the synthetic technique they employed [15]. Although there are various methods of preparing nanoparticles for various applications, the use 
of organometallic surfactant precursors is considered to generate products with better characteristics compared to those from other routes [36].

\section{Preparation and Characterisation}

There is a variety of approaches that can be employed for the synthesis of organometallic surfactants. Ionic surfactants as starting materials in the presence of alkyl ammonium salts can be employed [29]. This process is considered to be straightforward in comparison to traditional synthetic routes. Other reports have indicated the use of norbonenemethyl amine with substituted alkanoic acids of various carbon chain length (degree of alkylation) [4]. Jaeger et al. (2001) employed a cobalt complex anion and EDTA (ethylenediaminetetraacetic acid, Figure 4) in the synthesis of a novel Cobalt (iii) surfactant [14]. Some studies, on the other hand, employed ion-exchange techniques from metal hydroxides in the synthesis of double metal surfactant films [23]. A Niobium based surfactant capable of self-assembly has also been reported. It was produced from a long chain amine and a Niobium salt. Water was used in the preparation process and the precipitate was aged for a week under high temperature that resulted into a white powder that was successfully characterised [20]. It should be noted that some reactions can require the use of inert atmosphere such as those reported by Kim et al. (2003) where a Palladium surfactant was produced from a surfactant precursor in a tioctylphosphine reagent [37]. In contrast to most reports where organic solvents were used, a cheap, safer and more environmentally friendly procedure exist where water can be used as the solvent [21].

\section{Routes to Understanding Structure and Functionality}

Characterisation of organometallic surfactants can fall into broad categories of structure, composition and properties. These categories are usually interrelated. To fully understand structure of many of the surfactants, a range of analytical techniques can be used on the basis of elemental analysis, spectroscopy, diffraction [15] and microscopy [38]. Other relevant techniques that can also be employed include cytotoxicity and biological activity studies [39], combustion analysis [14] [40], auto-oxidation studies [16], and pyrolysis [41].

Spectroscopy being the study of the interaction between constituents of a material with radiant energy allows characterisation basis for analysis and identification of atoms and functional groups in chemical compounds. Regarding the characterisation of organometallic surfactants, many spectroscopic techniques have been found to be relevant. Some of the techniques commonly reported in the literature include: infra red (IR) spectroscopy [9] [14] [35] [37] [42] for functional group identification, nuclear magnetic resonance (NMR) for proton group/environment identification and UV-Visible spectroscopy [14].

Thermal analyses techniques including thermogravimetric analysis (TGA), differential scanning calorimetry (DSC) and differential thermal analysis/measurement (DTA) have been reportedly used with great importance [35]. Thermal analysis provides a basis for understanding transition temperatures, thermal degradation or decompositions of materials, thus, understanding their thermal stability. In terms of crystal nature and self-assembly studies, X-ray diffraction [42] and microscopy have been reportedly used to characterise organometallic surfactants [17] [20] [25]. The analysis of the metal ion or atom present is also of great importance. Atomic absorption spectroscopy [23] has been reported to be useful in this regard for both qualitative analysis and quantitative analysis.

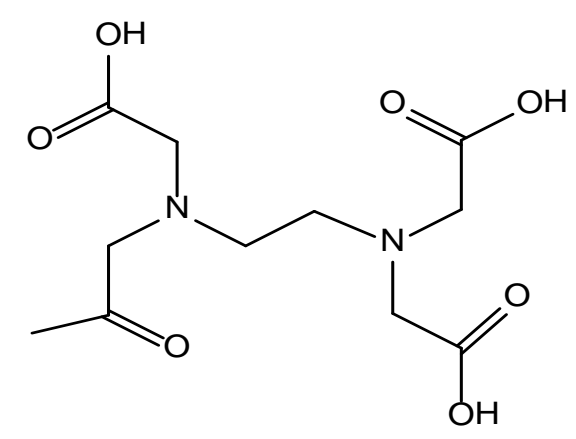

Figure 4. Chemical structure of ethylenediaminetetraaceticacid (EDTA). 


\section{End Applications}

\subsection{Conventional Applications}

Many early studies and reports on organometallic surfactants concern their promising application in tackling extremely difficult and complex industrial processes such as being used to clean mechanical parts in industrial processes and equipment. These materials are also considered to be structure-modifiers of the hydrocarbon components during the removal of oil or wax in industrial processes [43]. Another important area where organometallic surfactants find considerable application is catalysis. Here, they are used as catalysts [5] [7] [10] [21] [34] [44] in many industrial processes depending on the type of chemical reaction that is involved. They also find application as stabilisers when used in dispersion systems [17] and as electrically conductive materials for use in electronics due to their magnetic and conductive properties [8].

\subsection{More Recent Applications}

Recent studies have focused on the diverse applications of organometallic surfactants in drug delivery and other medical/medicinal applications. For example, they have actively been used in hormone and cancer treatments [26]. One common requirement for application in biological systems, for most materials used including organometallic surfactants, is biodegradability and bio-compatibility [45]. Therefore, for any intended biomedical application, it is essential that these conditions are met prior to administration or encapsulation.

In a recent report, An and co-workers (2009) considered an Osmium based organometallic surfactant to be extremely useful in the stabilisation of some nanoparticles that possess outstanding "anti-microbial activities". The organometallics were found to have activity against some trends of bacteria including E. coli and S. aureus [34]. Earlier in 2007, the same organometallic surfactants were reported by Ahmed and Leong, where they were used as reaction stabilisers [22]. The stabilisation capabilities possessed by organometallic surfactants are relative to their amphiphilic nature possessing both hydrophilic ends and hydrophobic ends.

As stated elsewhere in this review, organometallic surfactants have been successfully used over the years in the production of nanopartcle shells [42]. The process would include the decomposition of surfactant precursors under a set of experimental conditions to generate particles which have sizes in the nanometre range. Some Silver and Platinum nanoparticles have been reportedly produced through analogous processes [34]. Other routes for the production of Silver nanoparticles have also been well researched and documented [22] [33].

In 2004, Son et al. have reported the generation of single nanoparticle shells of Nickel and Palladium from organometallic surfactants. Their study unlike many others, included a report on the synthesis of a double metal Ni/Pd "core shell nanoparticles" where the Pd shells were overlaid on the Ni core [15]. Many nano-molecular assemblies generated in a similar manner from organometallic surfactants have been documented in the literature and have proved to possess outstanding characteristics paving a way for many applications including optical, electrical and magnetic uses [17] [36].

In addition to the application of organometallics in drug delivery [27] [28] and the production of nanoparticles, other considerable areas of application include high technology areas as electric printing, magnetic recording and bio-technology [46]. In the past decade, the uses of organometallic surfactants are normally centred on modifying viscosity and surface properties of various chemical formulations. Titanium and Zirconium based organometallic surface active agents were reported to have considerable usage in this area [19]. Another objective area of consideration is the use of organometallics in the green sciences. They have been considered ideal materials that can be used to coat some ceramic powders in the generation of "green and fine dense" articles [30].

\section{Conclusion}

This review has highlighted many recent developments that concern organometallic surfactants covering their nature, being transition metal-based or non-transition metal-based, as reported in the literature. This review has also discussed their outstanding properties. It has been shown that their metal content coupled with their properties has paved a way for their many applications, including, the preparation of nanoparticles. Various synthetic methods exist for their preparation and assembly. Some of the basic characterisation techniques included molecular spectroscopy, thermal analysis and microscopy. However, their structure-based applications are still under study [31] and some future studies would be needed for a full understanding of the metal-surfactant interactions [25]. It is expected that in the future, more studies would focus on their prospects for use in the synthesis of 
fine chemicals [44], on their improved properties [47] and on general application of surfactants in the production of "optoelectric materials and nanoparticles" [48].

\section{References}

[1] Rein, M., Ed. (2002) Drop-Surface Interaction. Springer Wien, New York.

[2] Atwood, J.L., Ed. (2004) Encyclopedia of Supramolecular Chemistry. New York, 854-861.

[3] Asinger, F., Ed. (1969) Chemistry, Physics and Application of Surface Active Substances: Chemistry of Surface Active Substances.

[4] Bordes, R., Rbii, K. and Gonzales-Perez, A. (2007) Novel Polymerizable Surfactants from 1:1 Mixtures of Alkylcarboxylic Acids and Norbornene Methylenamine. Langmuir, 23, 7526-7530. http://dx.doi.org/10.1021/la700521p

[5] Mancin, F., Scrimin, P. and Tecellia, P. (2009) Amphiphilic Metalloaggregates: Catalysis, Transport, and Sensing. Coordination Chemistry Reviews, 253, 2150-2165. http://dx.doi.org/10.1016/j.ccr.2009.03.015

[6] Trickett, K., Xing, D.Z. and Eastoe, J. (2007) Hydrocarbon Metallosurfactants for $\mathrm{CO}_{2}$. Langmuir.

[7] Tian, H.Y., Li, H.J. and Chen, Y.J. (2002) Development of Highly Effective Encapsulating Surfactants for Mukaiyama Aldol Reactions in Water. Industrial \& Engineering Chemistry Research, 41, 4523-4527. http://dx.doi.org/10.1021/ie010782k

[8] Chagnon, M.S.L. (1992) Superparamagnetic Liquid Colloids. Omni Quest Corporation, Massachusetts.

[9] Joshi, P.N. and McCauley, R.A. (1994) Metal-Organic Surfactants as Sintering Aids for Silicon-Nitride in an AqueousMedium. Journal of the American Ceramic Society, 77, 2926-2934. http://dx.doi.org/10.1111/j.1151-2916.1994.tb04526.x

[10] Lang, N., Delichere, P. and Tuel, A. (2002) Post-Synthesis Introduction of Transition Metals in Surfactant-Containing MCM-41 Materials. Microporous and Mesoporous Materials, 56, 203-217. http://dx.doi.org/10.1016/S1387-1811(02)00486-9

[11] Datta, A., Dasgupta, S. and Agarwal, M. (2005) Mesolamellar VPO Phases Obtained by Incorporating Long Chain Alkyl Amine Surfactants into the Layered Vanadium Phosphate Dihydrate Phase. Microporous and Mesoporous Materials, 83, 114-124. http://dx.doi.org/10.1016/j.micromeso.2005.03.019

[12] Chaubey, G.S., Barcena, C. and Poudyal, N. (2007) Synthesis and Stabilization of FeCo Nanoparticles. Journal of the American Chemical Society, 129, 7214-7221. http://dx.doi.org/10.1021/ja0708969

[13] Liang, G.D., Xu, J.T. and Wang, X.S. (2009) Synthesis and Characterization of Organometallic Coordination Polymer Nanoshells of Prussian Blue Using Miniemulsion Periphery Polymerization (MEPP). Journal of the American Chemical Society, 131, 5378-5381. http://dx.doi.org/10.1021/ja900516a

[14] Jaeger, D.A., Jose, R. and Mendoza, A. (2007) Surfactant Transition Metal Chelates. Colloids and Surfaces APhysicochemical and Engineering Aspects, 302, 186-196. http://dx.doi.org/10.1016/j.colsurfa.2007.02.021

[15] Son, S.U., Jang, Y. and Park, J. (2004) Designed Synthesis of Atom-Economical Pd/Ni Bimetallic Nanoparticle-Based Catalysts for Sonogashira Coupling Reactions. Journal of the American Chemical Society, 126, 5026-5027. http://dx.doi.org/10.1021/ja039757r

[16] Lim, Y.Y., Tan, E.H.L. and Foong, P.C. (1993) Autooxidation of Catechols in Solutions of Copper(II) Surfactants and Hydrated Metal-Ions in Sodium Dodecyl-Sulfate. Journal of Molecular Catalysis, 85, 173-181. http://dx.doi.org/10.1016/0304-5102(93)80100-9

[17] Rataboul, F., Nayral, C. and Casanove, M.J. (2002) Synthesis and Characterization of Monodisperse Zinc and Zinc Oxide Nanoparticles from the Organometallic Precursor $\left[\mathrm{Zn}\left(\mathrm{C}_{6} \mathrm{H}_{11}\right)_{2}\right]$. Journal of Organometallic Chemistry, 643, 307312. http://dx.doi.org/10.1016/S0022-328X(01)01378-X

[18] Buschow, K.H., Ed. (2001) Encyclopedia of Materials—Science and Technology. Elsevier, New York, 5342-5346.

[19] Krug, G. and Danforth, S.C. (1988) Modification of SiC Whisker and Silicon Powder Surfaces Using Organometallic Surfactant. Proceedings of the 3rd Symposium for Ceramic Materials and Components for Engines, Las Vegas, 27-30 November 1988.

[20] David, M.A. and Ying, J.Y. (1996) Synthesis of a Stable Hexagonally Packed Mesoporous Niobium Oxide Molecular Sieve through a Novel Ligand-Assisted Ternplating Mechanism. Angewandte Chemie International Edition in English, 35, 426-430. http://dx.doi.org/10.1002/anie.199604261

[21] Deleersnyder, K., Shi, D.Z. and Binnemans, K. (2008) Lanthanide-Surfactant-Combined Catalysts for the Allylation of Benzaldehyde with Tetraallyltin in Aqueous Solutions. Journal of Alloys and Compounds, 451, 418-421. http://dx.doi.org/10.1016/j.jallcom.2007.04.161

[22] Ahmed, M.O.E., Li, C. and Leong, W.K. (2007) Luminescent Silver Nanoparticles Stabilised by a Crown Ether 
Capped with an Organometallic Cluster. Journal of Organometallic Chemistry, 692, 3474-3478. http://dx.doi.org/10.1016/j.jorganchem.2007.04.018

[23] Kopka, H., Beneke, K. and Lagaly, G. (1988) Anionic Surfactants between Double Metal Hydroxide Layers. Journal of Colloid and Interface Science, 123, 427-436. http://dx.doi.org/10.1016/0021-9797(88)90263-9

[24] Liu, G.X. and Puddephatt, R.J. (1996) Model Reactions for the Synthesis of Organometallic Dendrimers Containing Platinum and Palladium. Inorganica Chimica Acta, 251, 319-323. http://dx.doi.org/10.1016/S0020-1693(96)05285-1

[25] Bucher, S., Hormes, J. and Modrow, H. (2002) Interaction between Core and Protection Shell of N(butyl) $)_{4} \mathrm{Cl}-$ and

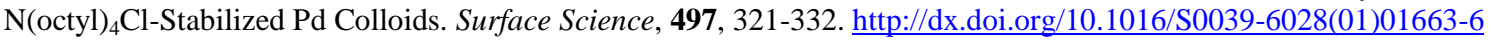

[26] Allard, E., Passirani, C. and Parcion, E. (2008) Lipid Nanocapsules Loaded with an Organometallic Tamoxifen Derivative as a Novel Drug-Carrier System for Experimental Malignant Gliomas. Journal of Controlled Release, 130, 146153. http://dx.doi.org/10.1016/j.jconrel.2008.05.027

[27] Mertins, O., Buriez, O. and Labbe, E. (2009) Further Insights into Hydrophobic Interactions between FerrocenylTamoxifen Drugs and Non-Polar Molecular Architectures at Electrode Surfaces. Journal of Electroanalytical Chemistry, 635, 13-19. http://dx.doi.org/10.1016/j.jelechem.2009.07.015

[28] Nguyen, A., Top, S. and Vessierces, A. (2007) Organometallic Analogues of Tamoxifen: Effect of the Amino SideChain Replacement by a Carbonyl Ferrocenyl Moiety in Hydroxytamoxifen. Journal of Organometallic Chemistry, 692, 1219-1225. http://dx.doi.org/10.1016/j.jorganchem.2006.11.016

[29] Hamoudi, S., Yang, Y. and Moudrakovski, I.L. (2001) Synthesis of Porous Organosilicates in the Presence of Alkytrimethylammonium Chlorides: Effect of the Alkyl Chain Length. Journal of Physical Chemistry B, 105, 9118-9123. http://dx.doi.org/10.1021/jp011195f

[30] Mccauley, R.A. and Remco, D.J. (1993) Ceramic Powder Useful in the Manufacture of Green and Densified Fired Ceramic Articles. United States Patent No. 5273942.

[31] Schatzschneider, U. and Nolte, N.M. (2006) New Principles in Medicinal Organometallic Chemistry. Angewandte Chemie International Edition, 245, 1504-1507. http://dx.doi.org/10.1002/anie.200504604

[32] Farrusseng, D., Aguado, S. and Pinel, C. (2009) Metal-Organic Frameworks: Opportunities for Catalysis. Angewandte Chemie International Edition, 48, 7502-7513. http://dx.doi.org/10.1002/anie.200806063

[33] Ahmed, M.O.E. and Leong, W.K. (2006) Colloidal Silver Nanoparticles Stabilized by a Water-Soluble Triosmium Cluster. Journal of Organometallic Chemistry, 691, 1055-1060. http://dx.doi.org/10.1016/j.jorganchem.2005.11.015

[34] An, J., Wang, D.S. and Luo, Q.Z. (2009) Antimicrobial Active Silver Nanoparticles and Silver/Polystyrene Core-Shell Nanoparticles Prepared in Room-Temperature Ionic Liquid. Materials Science and Engineering: C, 29, 1984-1989. http://dx.doi.org/10.1016/j.msec.2009.03.015

[35] Park, J., An, K.J. and Hwang, Y.S. (2004) Ultra-Large-Scale Syntheses of Monodisperse Nanocrystals. Nature Materials, 3, 891-895 http://dx.doi.org/10.1038/nmat1251

[36] Howes, P., Green, M. and Johnston, C. (2008) Synthesis and Shape Control of Mercury Selenide (HgSe) Quantum Dots. Journal of Materials Chemistry, 18, 3474-3480. http://dx.doi.org/10.1039/b804158j

[37] Kim, S.W., Park, J. and Jang, Y. (2003) Synthesis of Monodisperse Palladium Nanoparticles. Nano Letters, 3, 12891291. http://dx.doi.org/10.1021/nl0343405

[38] Tang, Z.Y. and Wang, E.K. (2001) Potential-Induced Transformation for Surfactant Aggregates on a Metal Surface. Journal of Electroanalytical Chemistry, 496, 82-87. http://dx.doi.org/10.1016/S0022-0728(00)00370-3

[39] Nguyen, J., Reul, R. and Betz, T. (2009) Nanocomposites of Lung Surfactant and Biodegradable Cationic Nanoparticles Improve Transfection Efficiency to Lung Cells. Journal of Controlled Release, 140, 47-54. http://dx.doi.org/10.1016/j.jconrel.2009.07.017

[40] Bohle, D.S., Goodson, P.A. and Jaeger, D.A. (2001) Functional Nickel Thiosalen Complexes: Structure and Solid-State Packing of a Transition Metal-Based Surfactant. Inorganica Chimica Acta, 312, 210-214. http://dx.doi.org/10.1016/S0020-1693(00)00342-X

[41] Diaz, C. and Valenzuela, M.L. (2006) Photoluminiscent Manganese Nanoparticles from Solid State Polyphosphazenes Organometallic Derivatives. Journal of Inorganic and Organometallic Polymers and Materials, 16, 123-128. http://dx.doi.org/10.1007/s10904-006-9035-X

[42] Geng, B.Y., Liu, X.W. and Ma, J.Z. (2007) A New Nonhydrolytic Single-Precursor Approach to Surfactant-Capped Nanocrystals of Transition Metal Sulfides. Materials Science and Engineering B-Solid State Materials for Advanced Technology, 145, 17-22. http://dx.doi.org/10.1016/j.mseb.2007.09.065

[43] Kazakova, L.P., Gundyreb, A.A. and Klochkova, N.A. (1986) Application of Organometallic Surfactants in Production of Lubricating Oils and Microcrystalline Waxes. Chemistry and Technology of Fuels and Oils, 22, 17-19. http://dx.doi.org/10.1007/BF00736111 
[44] Cornils, B. and Herrmann, W.A., Eds. (2004) Aqueous-Phase Organometallic Catalysis. Wiley-VCH, Weinheim, 171. http://dx.doi.org/10.1002/3527602488

[45] Acosta, E.J., Nguyen, T. and Witthayapanyanon, A. (2005) Linker-Based Bio-Compatible Microemulsions. Environmental Science \& Technology, 39, 1275-1282. http://dx.doi.org/10.1021/es049010g

[46] Banez, M.V.D., Robinson, K.L. and Vamvakaki, M. (2000) Synthesis of Novel Cationic Polymeric Surfactants. Polymer, 41, 8501-8511. http://dx.doi.org/10.1016/S0032-3861(00)00217-2

[47] Yamamoto, A. (2001) Organometallic Chemistry. Past, Present, and Future. Pure and Applied Chemistry, 73, $205-208$. http://dx.doi.org/10.1351/pac200173020205

[48] Fong, C.Y., Watson, M.D. and Yang, L.H. (2002) Surfactant-Mediated Growth of Semiconductor Materials. Modelling and Simulation in Materials Science and Engineering, 10, R61-R77. http://dx.doi.org/10.1088/0965-0393/10/5/201 